\title{
Biocontrol of Diamondback Moth Larvae Tolerant to Bt-toxin Dipel® by the Entomopathogenic Fungus Metarhizium anisopliae (Metschn.) Sorokin (Hypocreales, Ascomycota)
}

\author{
Yacoub Batta* \\ Department of Plant Production \& Protection, Faculty of Agriculture and Veterinary Medicine, An-Najah National University, Palestine
}

Submission: September 22, 2018, Published: October 09, 2018

"Corresponding author: Yacoub Batta, Department of Plant Production \& Protection, Faculty of Agriculture and Veterinary Medicine, An-Najah National University, Nablus, West Bank, Palestine, Tel: 0097292360105; 00972599358370; Email: yabatta@najah.edu

\begin{abstract}
Diamondback moth Plutella xtlostella (Plutellidae, Lepidoptera) is a destructive insect on plants of family Cruciferae. Bacillus thuringiensis toxins, abbreviated Bt-toxins, are biopesticides that could be used for control of larvae of lepidopterous insects. The efficacy of these biopesticides usually decreases due to the development of tolerance to these pesticides by the treated insects. However, this decrease could be compensated by applying biocontrol agents such as entomopathogenic fungi. The objective of the present research was to test the efficacy of Metarhizium anisopliae, as an entomopathogenic fungus, against susceptible and tolerant populations of P.xylostella larvae to Bt-toxin Dipel®. For this purpose, a series of fungus concentrations were used against susceptible and tolerant populations of $P$. xylostella larvae to Dipel ${ }^{\circledR}$. Results indicated that there were significant differences (at $\mathrm{P}=0.05$ ) between the concentrations of $M$. anisopliae that were used for the treatment of Bt-tolerant and susceptible larvae of P. xylostella. The biocontrol efficacy of M. anisopliae was higher in the susceptible larvae than that in the Bt-tolerant larvae at the concentrations that exceeded $1 \times 10^{\wedge} 6$ conidia/ml. Probit analysis indicated that the LC50 of the fungus concentrations used for the treatment was $7.70 \times 10^{\wedge} 6$ conidia $/ \mathrm{ml}$ for the Bt-tolerant larvae vs. $1.34 \times 10^{\wedge} 5$ conidia $/ \mathrm{ml}$ for the susceptible larvae. In conclusion, in spite of the development of low value cross-tolerance in Bt-tolerant $P$. xylostella larvae to M. anisopliae treatment, there is a good possibility for including this fungus in the integrated control of the insect when develops tolerance to Bt-toxin Dipelß because of high biocontrol efficacy of the fungus.
\end{abstract}

Keywords: Biocontrol efficacy; Metarhizium anisopliae; Plutella xylostella; Bt-toxin Dipel®; Susceptible population; Tolerant population

Abbreviations: EPF: Entomopathogenic Fungi; SDA: Sabouraud Dextrose Agar; RR: Resistance Ratio

\section{Introduction}

Plutella xylostella is an insect pest on cruciferous plants such as cabbage, cauliflower, radish, turnip, beet root, mustard and rape seed [1,2]. The damaging form of this insect is the larva that feeds on the leaves of these plants making large holes in the attacked leaves or causing leaf skeletonization at heavy infestation. Therefore, the yield loss in the attacked plants varies from $31-100 \%[2,3]$. Control of this insect is usually practiced by application of various synthetic chemical insecticides such as Emamectin benzoate $\left(\right.$ Proclaim $^{\circledR}$ ), Spinosad (Success ${ }^{\circledR}$ ) and Indoxacarb $\left(\right.$ Avatar $\left.^{\circledR}\right)$ [4-10], but the frequent application of large doses of these insecticides causes the development of resistance by target site mutations or tolerance by inducible upregulation of immune and metabolic activities [6,9-16]. Alternative approach to synthetic chemical insecticides is the application of biopesticides especially the commercial formulations of Bacillus thuringiensis toxins known as Bt-toxins such as Dipe ${ }^{\circledR}$, Cry and Cyt $[11,12,15-$ 17]. However, tolerance to these biopesticides especially the Bt- toxins may evolve frequently due to induction of immune defense reactions in the treated larvae $[11,13-16,18]$. To decrease the effect of tolerance developed to these biopesticides, biocontrol agents such as entomopathogenic fungi (EPF) could be involved in the integrated management of $P$. xylostella. These fungi are currently being developed for biocontrol of many insect species [19-27]. Given that Bt-tolerant larvae have elevated immune and metabolic activities [12-14], we wanted to examine the assumption of that if EPF are used for biocontrol of tolerant populations of $P$. xylostella larvae to Dipel ${ }^{\circledR}$, the control efficacy of the insect will be improved accordingly.

Recently, formulated forms of EPF have been used against various insect species, and invert emulsion formulation (water-in-oil type) is used as a promising formulation for these entomopathogens when applied as biocontrol agents of insects [28-35]. Few investigators have reported the potential use of EPF as biocontrol agent of $P$. xylostella larvae [36-39]. However, 
no investigations have been conducted on using these pathogens for control of P. xylostella larvae that have developed tolerance to the widely used commercial formulations of Bt-toxins including Dipel $^{\circledR}$. Therefore, the objectives of this study were:

a. To test the efficacy of treatment with M. anisopliae (strain MA1) against susceptible and tolerant P. xylostella larval population to Bt-toxin Dipel ${ }^{\circledR}$.

b. To compare the susceptibility of both larval populations of the insect to treatments with M. anisopliae.

c. To discuss the reasons for including M. anisopliae in integrated control of $P$. xylostella larval populations that have developed tolerance to Bt-toxin Dipel ${ }^{\circledR}$.

\section{Materials and Methods}

\section{Strain of Metarhizium anisopliae used in bioassays}

Strain MA1 of M. anisopliae was used in bioassays of the present study. This strain was isolated from infected adults and larvae of the ground beetles:

Carabus nemoralis L. (Carabidae: Coleoptera) with this fungus. The isolation was done, at first, on a selective medium: Sabouraud Dextrose Agar (SDA) + Chloramphenicol (250mg/L) then, pure cultures of this isolate was obtained from monosporic culture of the fungus on SDA.

\section{Populations of Plutella xylostella larvae used in Bioas- says}

A susceptible population of P. xylostella to Bt-toxin treatments had been used in bioassays. This population was considered susceptible because their cultures were not exposed to any type of insecticides, including Bt-toxins, during their rearing for several years so large number of generations were developed which were considered susceptible population of $P$. xylostella. Also, the cultures had been maintained on cabbage seedling leaves (Brassica oleracae var. capitata cv. Green Coronet) grown under the insectary conditions $\left(25 \pm 1.0^{\circ} \mathrm{C}, 14 / 10 \mathrm{~h}, \mathrm{~L} / \mathrm{D}\right.$ photoperiod) in separately-caged cultures at the faculty of Agriculture and Veterinary Medicine, An-Najah National University, Nablus, Palestinian Territories. To increase larval numbers on a large scale for bioassays, neonate larvae were reared on canola (Brassica napus, var. Monty) seedlings stands grown on vermiculite in $500 \mathrm{ml}$ Plaspak ${ }^{\circledR}$ plastic pots. Cabbage leaves off cuts from leaf disk preparation were added periodically, when required for developing larvae. A thin layer of honey on masking tape and $10 \%$ honey solution containing $0.1 \%$ sorbic acid were provided as food source for adult moths of $P$. xylostella. The strain of susceptible population was also used as a reference strain for comparison with Bt- tolerant population of this insect.

A field population of $P$. xylostella larvae and adults that were tolerant to the Bt-toxin Dipel ${ }^{\circledR}$ was used in bioassays as Bttolerant population. This population was tolerant to low-medium levels of the Bt-toxin formulations without any over target site mutation. It was found that in the absence of Bt-exposure, the tolerance disappeared, an indication that the tolerance was due to the transient induction of immune and metabolic genes $[13,14]$. Therefore, to ensure the development of tolerance in the field population, larvae of this population were fed on cabbage seedlings (B. oleracae var. capitata cv. Green Coronet) sprayed with 100 ppm of aqueous solution of Dipel ${ }^{\circledR}$ formulation for 2 successive generations (F2 was used in bioassays) and kept in the insectary at $25 \pm 1.0^{\circ} \mathrm{C}(14 / 10 \mathrm{~h}, \mathrm{~L} / \mathrm{D}$ photoperiod $)$ in separately-caged cultures at the faculty of Agriculture and Veterinary Medicine, An-Najah National University, Nablus, Palestinian Territories. One hundred ppm of aqueous solution of Dipe ${ }^{\circledR}$ was periodically prepared then sprayed onto cabbage seedlings that were left to dry before being introduced into the Bt-tolerant culture to increase larval numbers on a large scale for bioassays. A thin layer of honey on masking tape and $10 \%$ honey solution containing $0.1 \%$ sorbic acid were provided as food source for adult moths during rearing.

\section{Bioassays of the Study}

Before each formal bioassay, a preliminary assay was carried out using a broad range of concentrations of the fungus preparation containing known conidial concentration to achieve two purposes: the first, to determine the proper concentrations that should be used for the formal assay. The second, to confirm the presence of tolerance to Bt-toxins in the population of the insect known as Bt-tolerant population before carrying out the formal assay by comparing the treatment effect with the fungus on the insect mortality of susceptible and tolerant larvae. Moreover, Tween $20(0.1 \% \mathrm{v} / \mathrm{v})$ was added to the conidial suspensions of the fungus to get the conidia into suspension so homogenous conidial suspensions were obtained. Also, the germination test for the conidia was systematically done before each formal bioassay to ensure a high viability of conidia involved in the fungus preparations for bioassays.

For formal bioassays, cabbage leaf disks of $90 \mathrm{~mm}$ diameter were cut from washed cabbage leaves taken from healthy eightweek-old plants grown under the greenhouse conditions at faculty of Agriculture and Veterinary Medicine, An-Najah National University, Nablus, the Palestinian Territories. The leaf disks were then embedded into agar that had been, first, sterilized in an autoclave then poured into $90 \mathrm{~mm}$ diameter Petri dishes with the underside of leaf disks facing upwards. Ten of the third instar larvae of P. xylostella were placed on each leaf disk in a Petri dish, and then each dish was sprayed with a precise deposit of each concentration $(4.0 \mathrm{ml})$ of fungus conidial suspension using a small calibrated fine jet sprayer (200ml capacity). The dishes were then covered with a plastic film that was secured with a rubber band, and then about 200 to 250 tiny holes were then punched into the plastic film using a very fine needle to allow the exchange of air and to insure a good aeration for the incubated larvae. The treated dishes were then kept in an incubator at $25 \pm 0.5^{\circ} \mathrm{C}(14 / 10 \mathrm{~h}, \mathrm{~L} / \mathrm{D}$ photoperiod $)$ and the treatment effect at the different concentrations was assessed 96 hours after the treatment. Each formal bioassay includes 10 concentrations of the fungus preparation containing the conidia starting from $1 \times 10^{\wedge} 9$ conidia/ml to 0 conidia/ml (sterile deionized water as a control). To prepare the concentrations used in bioassays, successive dilutions of 10 times were performed using 
the highest concentration $\left(1 \times 10^{\wedge} 9\right.$ conidia/ml) until reaching the lowest one (0 conidia/ml).

Each concentration used in bioassays was replicated 4 times represented by 4 Petri dishes with 4 leaf disks of $9 \mathrm{~cm}$ diameter and ten of the third instar larvae of P. xylostella (4 dishes represent 4 replications per fungus concentration). The successive dilutions were made up in sterile de-ionized water to obtain the specific concentrations using volumetric flasks. It is noteworthy to mention that bioassays carried out in both populations were run at the same time because this is essential for statistical comparison under the same conditions, and each bioassay for each concentration was repeated three times under the same experimental conditions for confirmation of the results. Moreover, there were no differences between the two populations used in bioassays other than tolerance to Bt-toxin.

\section{Assessment Method used in the Study}

The assessment of the treatment effects was done by counting dead and live P. xylostella larvae in each Petri dish and in each Results population after 96 hours of the treatment and then calculating the mortality percent of treated larvae. The mean \% of larval mortality was then calculated for each concentration of the fungus and comparison of the treatment effect was then carried out after statistical analysis.

\section{Statistical Analysis}

The data obtained from bioassays were statistically analyzed using ANOVA, F-test, and mean separation by Tukey's HSD test to determine the treatment effect with the fungus on P. xylostella larvae in Bt-susceptible and tolerant populations. A comparison of the means of mortality percent of Bt-susceptible and tolerant larvae at the different concentrations was conducted. Also, Probit analysis [40], was carried out to determine the median lethal concentration (LC50), ninety five percent confidence limits (95\% C.L.) and slope of the regression lines for the Bt-susceptible and tolerant larvae. The resistance ratio (RR) for the Bt-tolerant larvae in relation to the susceptible larvae was also calculated.

\section{Biocontrol efficacy of M. anisopliae against Bt-tolerant larvae of P. xylostella}

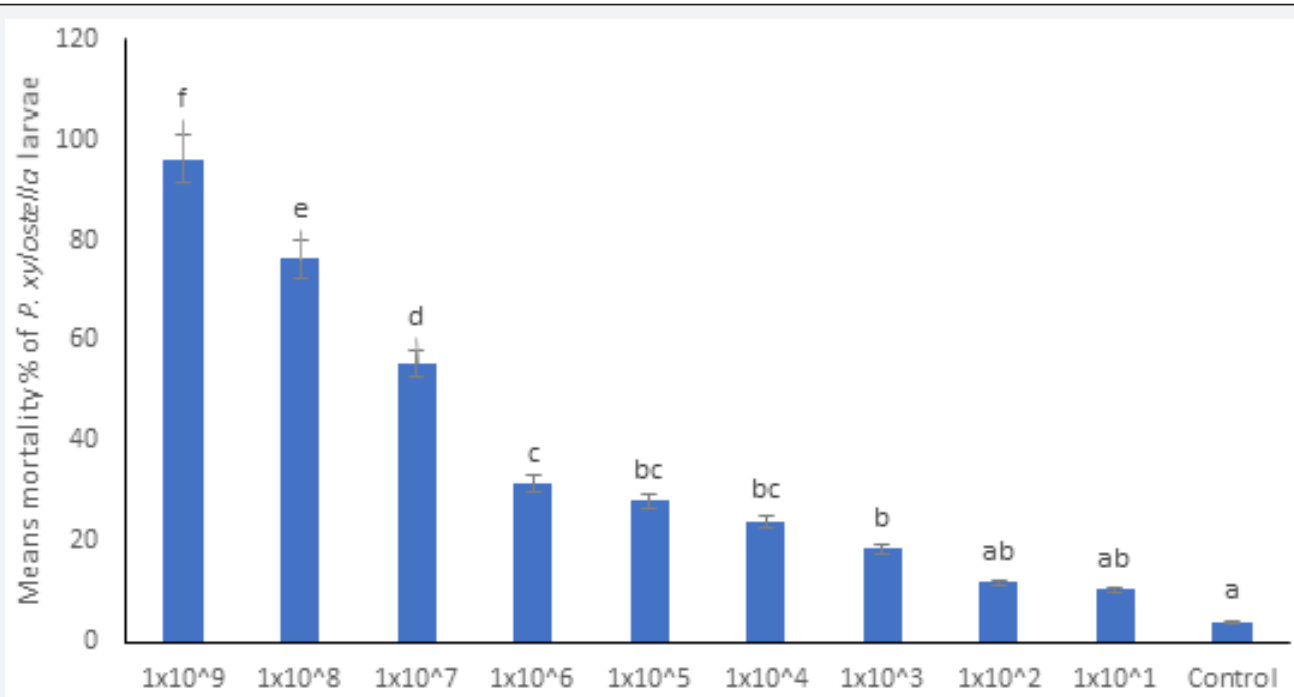

Concentration of $M$. anisopliae (conidia/ml)

Figure 1: Effect of treatment with different concentrations of the entomopathogenic fungus Metarhizium anisopliae (Strain MA1) on tolerant populations of Plutella xylostella larvae to Bt-toxin: Dipel ${ }^{\circledR}$ (F-test, ANOVA and Tukey's HSD test were used for comparison of means of mortality percent of Bt-tolerant $P$. xylostella larvae; means followed by the same letter are not significantly different at $P=0.05$ ).

Results indicated that significant differences (at $\mathrm{P}=0.05$ ) were obtained between the means of mortality percent of treated Bttolerant larvae of P. xylostella with M. anisopliae for the first four highest concentrations of the fungus used in bioassays: $1 \times 10^{\wedge} 9$, $1 \times 10^{\wedge} 8,1 \times 10^{\wedge} 7$ and $1 \times 10^{\wedge} 6$ conidia/ml (Figure 1). However, no significant differences were obtained between the means of mortality percent of treated Bt-tolerant larvae for the medium concentrations of the fungus used in the treatment: $1 \times 10^{\wedge} 5$, $1 \times 10^{\wedge} 4$ and $1 \times 10^{\wedge} 3$ conidia/ml (Figure 1 ). The median lethal concentration (LC50) for the Bt-tolerant larvae was 7.70x106 conidia/ml (Table 1). Overall, the treatment efficacy with the fungus was the highest for the higher concentrations of the fungus that exceeded $1 \times 10^{\wedge} 6$ conidia $/ \mathrm{ml}$.

\section{Biocontrol efficacy of M. anisopliae against Bt-suscepti- ble larvae of $P$. xylostella}

Significant differences (at $\mathrm{P}=0.05$ ) were obtained between the means of mortality percent of treated Bt-susceptible larvae of $P$. xylostella with $M$. anisopliae for thefirst threehighestconcentrations of the fungus: $1 \times 10^{\wedge} 9,1 \times 10^{\wedge} 8$ and $1 \times 10^{\wedge} 7$ conidia/ml (Figure 2). However, there were no significant differences between the means of mortality percent of treated Bt-susceptible larvae with 
the fungus for the two lower concentrations of the fungus: $1 \times 10^{\wedge} 7$ and $1 \times 10^{\wedge} 6$ conidia/ml (Figure 2 ). Also, no significant differences were obtained between the means of mortality percent of treated susceptible larvae with the fungus for the lower concentrations of the fungus: $1 \times 10^{\wedge} 5,1 \times 10^{\wedge} 4,1 \times 10^{\wedge} 3$ and $1 \times 10^{\wedge} 2$ conidia $/ \mathrm{ml}$
(Figure 2). The median lethal concentration (LC50) for the Btsusceptible larvae was $1.34 \times 10^{\wedge} 5$ conidia/ml (Table 1 ). Overall, efficacy of treatment with the fungus was the highest at higher concentrations that exceeded $1 \times 10^{\wedge} 7$ conidia $/ \mathrm{ml}$.

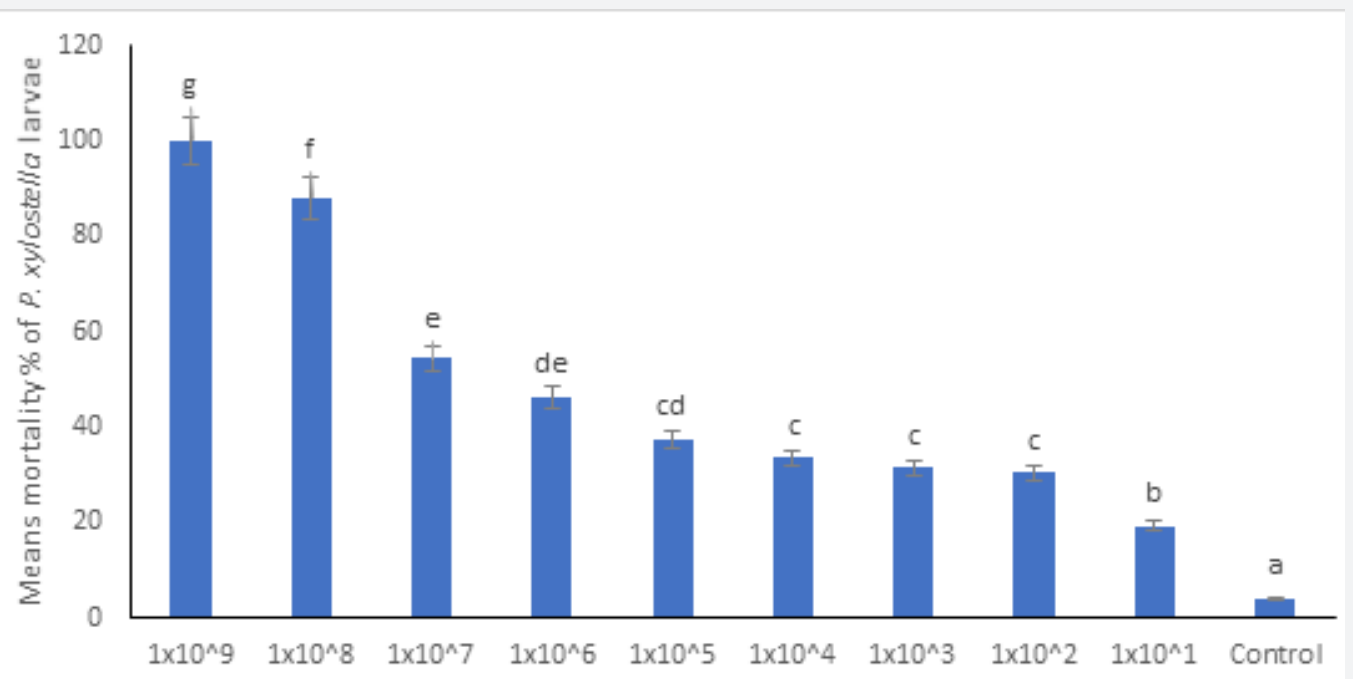

(0)

Concentration of $M$. anisopliae (conidia/ml)

Figure 2: Effect of treatment with different concentrations of the entomopathogenic fungus Metarhizium anisopliae (Strain MA1) on susceptible populations of Plutella xylostella larvae (F-test, ANOVA and Tukey's HSD test were used for comparison of means of mortality percent of susceptible $P$. xylostella larvae; means followed by the same letter are not significantly different at $P=0.05$ ).

\section{Comparison of biocontrol efficacy of $M$. anisopliae against Bt-tolerant and susceptible larvae of $P$. xylostella}

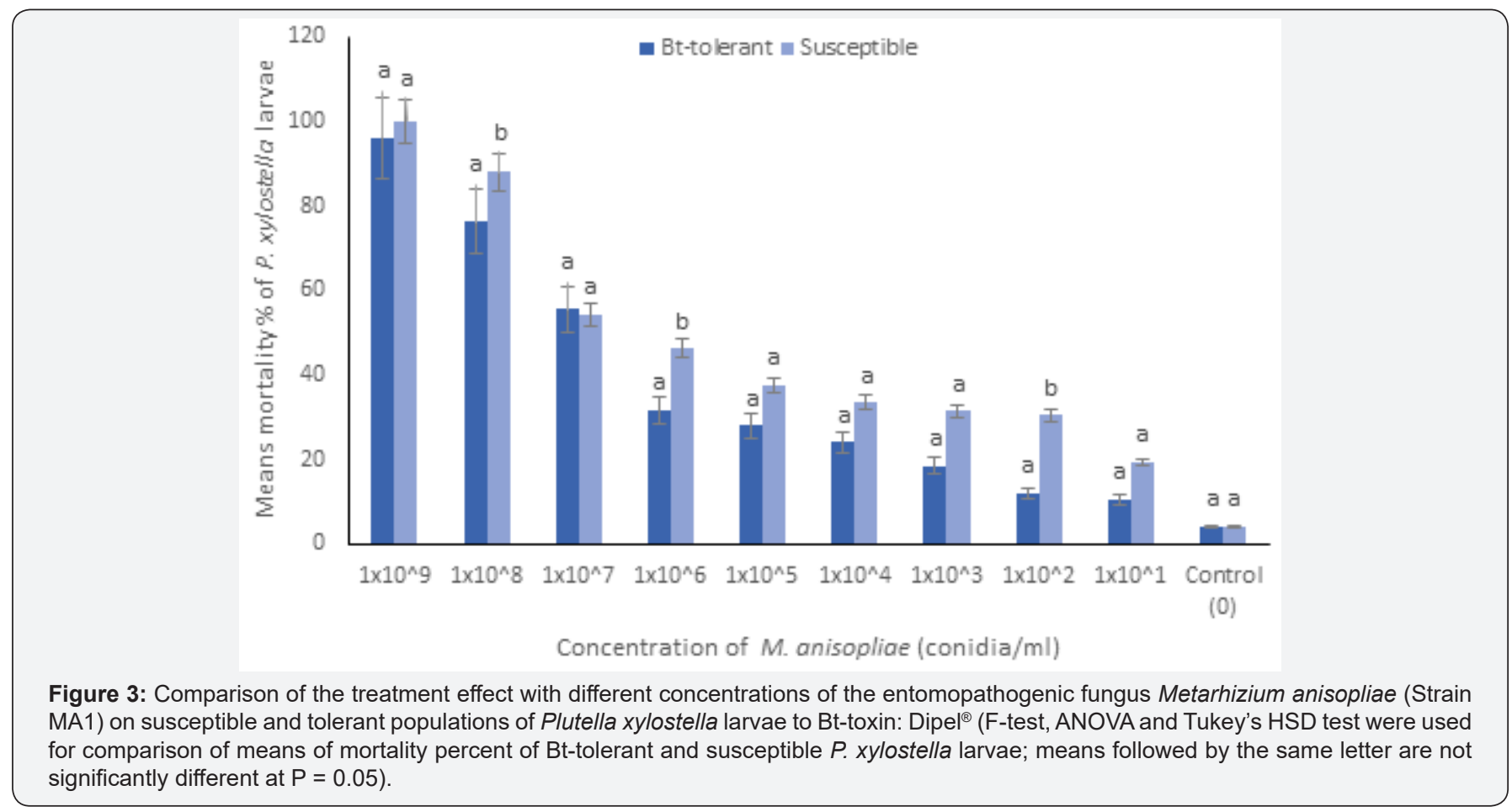

Results of the treatment effect of both populations of $P$. xylostella larvae with the fungus indicated that significant differences (at $\mathrm{P}=0.05$ ) were obtained between the means of mortality percent of treated larvae of the two populations at only two higher fungus concentrations: $1 \times 10^{\wedge} 6$ and $1 \times 10^{\wedge} 8$ conidia $/ \mathrm{ml}$ (Figure 3), but no significant differences were obtained between the two populations at the highest concentration of the fungus: $1 \times 10^{\wedge} 9$ conidia/ml (Figure 3). Therefore, the treatment efficacy 
with the fungus was higher in the susceptible population of $P$. xylostella larvae in comparison with the Bt-tolerant larvae (only at two concentrations of the fungus: $1 \times 10^{\wedge} 6$ and $1 \times 10^{\wedge} 8$ conidia $/ \mathrm{ml}$, but not at other higher concentrations).

Results of Probit analysis carried out on the two populations demonstrated that the median lethal concentration (LC50) for the Bt-tolerant larvae was $7.70 \times 10^{\wedge} 6$ conidia/ml vs. $1.34 \times 10^{\wedge} 5$ conidia/ml for the Bt-susceptible larvae and the ninety five percent confidence limits (95\% C.L.) and the slope of the regression lines for the Bt-susceptible and tolerant larvae were calculated at $0.38 \times 10^{\wedge} 5-5.00 \times 10^{\wedge} 5 ; 0.257 \pm 0.030$ and $1.18 \times 10^{\wedge} 6-$ $20.73 \times 10^{\wedge} 6 ; 0.675 \pm 0.159$, respectively (Table 1 ). The calculated resistance ratio (RR) was 57.46: 1.00 for the Bt-tolerant larvae in comparison with the susceptible larvae, respectively (Table 1). This indicates that the Bt-tolerant larvae was more tolerant to the treatment with the fungus by 57.46 times in proportion to the susceptible larvae.

Table 1: Probit analysis of the treatment effect of susceptible and tolerant populations of Plutella xylostella larvae to Bt-toxin: Dipel ${ }^{\circledR}$ using the entomopathogenic fungus Metarhizium anisopliae (Strain MA1).

\begin{tabular}{|c|c|c|}
\hline \multirow{2}{*}{ Probit Analysis } & Treated P. xylostella Lavae \\
\cline { 2 - 3 } & Bt-Tolerant & Bt-Susceptible \\
\hline LC50 $($ conidia $/ \mathrm{ml})$ & $7.70 \times 10^{\wedge}(-7700806.78)$ & $\left.1.34 \times 10^{\wedge} 5(133,702.010)\right)$ \\
\hline 95\% C.L. $($ conidia/ml) & $20,731,010.316)$ & $0.38 \times 10^{\wedge 5}-5.00 \times 10^{\wedge} 5(37,687.355-$ \\
\hline Slope & $0.675 \pm 0.159$ & $0.257 \pm 0.030$ \\
\hline Resistance Ratio (RR) & 57.46 & 1.00 \\
\hline
\end{tabular}

Overall results confirmed the potential use of the Fungus M. anisopliae as biocontrol agent of Bt-susceptible and tolerant populations of $P$. xylostella larvae. Although of the development of low cross tolerance in the Bt-tolerant population to the fungus, there were no significant differences between the susceptible and Bt-tolerant populations of the insect at medium concentrations of the fungus used against the two populations. Therefore, there is a good possibility of using the fungus as a potential biocontrol agent in the integrated control of Bt-tolerant population of P. xylostella larvae.

\section{Discussion}

In the present research, we proved that the entomopathogenic fungus (Metarhizium anisopliae: strain MA1) had high biocontrol efficacy against the susceptible and Bt-tolerant $P$. xylostella larvae at the concentrations $\geq 1 \times 10^{\wedge} 5$ conidia/ml with an LC50 of $1.34 \times 10^{\wedge} 5$ and $7.70 \times 10^{\wedge} 6$ conidia/ml for the susceptible and Bt-tolerant larvae, respectively. This indicates the possibility of using $M$. anisopliae as an effective biocontrol agent against the $P$. xylostella larvae that have developed tolerance to Bt-toxin Dipel ${ }^{\circledR}$ thus it can be used in pest management of this insect especially when develops tolerance to the biopesticide Dipel ${ }^{\circledR}$. The reasons for recommendation of the use of M. anisopliae in pest management of $P$. xylostella could be summarized as follows:

a. The fungus showed high biocontrol efficacy against the Bt-tolerant and susceptible populations of $P$. xylostella larvae. This efficacy reached at 96.1 and $100 \%$ as an average mortality percent in the Bt-tolerant and susceptible populations of P. xylostella larvae, respectively, within 96 hours after the treatment at the highest fungus concentration $\left(1 \times 10^{\wedge} 9\right.$ conidia/ml).

b. In spite of the tolerance development to Dipel ${ }^{\circledR}$ in the treated P. xylostella larvae (resistance ratio for the Bt-tolerant larvae to the susceptible larvae was 57.46:1.00), this ratio did not affect the overall efficacy of the fungus especially at higher concentrations $\left(1 \times 10^{\wedge}\right.$ to $1 \times 10^{\wedge 9}$ conidia $\left./ \mathrm{ml}\right)$.

c. The use of $M$. anisopliae proved effectiveness as biocontrol agents of other insect pests such as stored-grain insects [31,33,34],

d. Other reasons that may characterize the group of entomopathogenic fungi, in general, as effective biocontrol agents such as they are easy to isolate from infected host insects, easy to cultivate on culture media, easy to prepare from their cultures as conidial suspensions for being used against the targeted insects. Moreover, these microbial pesticides have no residual effect and do not contaminate the environment after application.

Few studies have been conducted using $M$. anisopliae as biocontrol agent of $P$. xylostella larvae $[37,41,42]$, the results of these studies have shown high efficacy against the treated insects. This result agreed with our results that demonstrated high efficacy due to the treatment of susceptible $P$. xylostella larvae with the fungus (M. anisopliae: strain MA1) at higher concentrations that exceed $1 \times 10^{\wedge} 8$ conidia/ml ( $88.1 \%$ of larval mortality or more). To date, no investigations have been conducted to determine the LC50's of M. anisopliae concentrations used as biocontrol agent of Bt-tolerant larvae of $P$. xylostella. Therefore, this research represents the first attempt to determine the LC50's of this entomopathogenic fungus when used as biocontrol agent of Bttolerant larvae and thus calculating the representative resistance ratio (RR). Although the calculated value of this ratio was quite low (57.46:1.00), it may suggest the development of certain type of cross-tolerance in the treated insects acquiring tolerance to Bttoxins such as Dipel ${ }^{\circledR}$ in our bioassays. One of the explanations for development of this type of cross-tolerance may be attributed to the induction of immune defense reactions in the treated larvae (e.g. induction of immune and metabolic genes according to 
Rahman et al. [12,13], by entomopathogenic fungi and Bt-toxins but further investigations are needed to be carried out to know the exact reason.

It is important to mention that mode of action of entomopathogenic fungi is different from that of Bt-toxins. For the mode of action of entomopathogenic fungi, it is well-known that these fungi enter the body cavity of attacked insects through the outer cuticle following germination of their conidia adhering the outer cuticle then growing and developing of fungus mycelium in the hemocoel causing finally obstruction of the body cavity and death of attacked insects [43-46]. However, Bt-toxins enter the insect through the ingestion then reach the digestive system of attacked insects where they are processed; the damage caused to the digestive system by the Bt-toxins is done by lysing the midgut epithelial cells by inserting into the target membrane and forming pores (pore-forming activities) allowing bacterial elicitors into the hemocoel $[17,47]$. Therefore, in case of developing a low-medium cross-tolerance to Bt-toxins and the fungus, the immune system of treated insects may respond with the activation of the immune response to microbial elicitors after the treatment with the fungus and Bt-toxin [12-14]. Ferre \& Van Rie [18], reviewed the biochemical changes and genetics of resistance to Bt-toxins and insecticidal crystal proteins by different species of insects treated with different formulations of these biopesticides. However, more research studies are recommended to be carried out in this respect to specify the exact mechanism of this type of cross-tolerance to the fungus and biopesticide in P. xylostella larvae.

\section{Conclusion}

Results obtained in the present research would suggest the potential for including $M$. anisopliae as biocontrol agent in the integrated control of $P$. xylostella larvae that have developed tolerance to Bt-toxin Dipel ${ }^{\circledR}$. Inclusion of this fungus was based on the higher efficacy levels that have been obtained when the fungus was applied against the Bt-tolerant larvae of the insect. The calculated values of the median lethal concentration (LC50) and resistance ratio (RR) of the fungus used against the Bt-tolerant larvae in proportion to the susceptible larvae would suggest the development of a certain type of cross-tolerance to the fungus and the biopesticide, but the low value of cross-tolerance did not affect the overall efficacy of the fungus that could be used as an effective biocontrol agent of the Bt-tolerant insect. Reasons for the recommendation of the use of $M$. anisopliae in pest management of $P$. xylostella larvae were discussed in the paper.

\section{Acknowledgement}

I would like to thank my colleagues in the Department of Plant Production and Protection, An-Najah National University for their help in editing the English language of the manuscript.

\section{Declaration of interest statement}

The author declares that he has no conflict of interests.

\section{References}

1. Sayyed AH, Attique MN, Khaliq A (2005) Stability of field-selected resistance to insecticides in Plutella xylostella (Lepidoptera, Plutellidae) from Pakistan. Journal of Applied Entomology 129(9-10): 542-547.

2. Talekar NS, Shelton AM (1993) Biology, Ecology and Management of the Diamondback Moth. Annu Rev of Entomol 38: 275-301.

3. Lingappa S, Basavanagoud K, Kulkarni KA, Patil RS, Kambrekar DN (2004) Threat to vegetable production by Diamondback Moth and its management strategies. Fruits and Vegetable Diseases, pp. 357-396.

4. Liu TX, Sparks AN, Chen W (2003) Toxicity, persistence and efficacy of indoxacarb and two other insecticides on Plutella xylostella (Lepidoptera: Plutellidae) immatures in cabbage. International Journal of Pest Management 49(3): 235-241.

5. McCann SF, Annis GD, Shapiro R, Piotrowski DW, Lahm GP, et al. (2001) The discovery of indoxacarb: oxadiazines as a new class of pyrazolinetype insecticides. Pest Manag Sci 57(2): 153-164.

6. Sayed AH, Omar D, Wright DJ (2004) Genetics of Spinosad resistance in a multi- resistant field-selected population of Plutella xylostella. Pest Manag Sci 60(8): 827- 832.

7. Syngenta (2004) Proclaim insecticides.

8. Thompson GD, Dutton R, Sparks TC (2000) Spinosad a case study: an example from natural products discovery program. Pest Management Science 56(8): 696-702.

9. Zhao JZ, Li YX, Collins HL, Gusukuma-Minuto L, Mau RFL, et al. (2002) Monitoring and characterization of Diamondback moth (Lepidoptera, Plutellidae) resistance to Spinosad. J Econ Entomol 95(2): 430-436.

10. Zhao JZ, Collins HL, Li YX, Mau RFL, Thompson GD, et al. (2006) Monitoring of Diamondback moth (Lepidoptera, Plutellidae) resistance to Spinosad, Indoxacarb and Emamectin benzoate. J Econ Entomol 99(1): 176-181.

11. Liang P, Gao XW, Zheng BZ (2003) Genetic basis of resistance and studies on cross-resistance in a population of diamondback moth, Plutella xylostella (Lepidoptera: Plutellidae). Pest Manag Sci 59(11): 1232-1236.

12. Ma G, Roberts H, Sarjan M, Featherstone N, Lahnstein J, et al. (2005) Is the mature endotoxin Cry1 Ac from Bacillus thuringiensis inactivated by a coagulation reaction in the gut lumen of resistant Helicoverpa armigera larvae? Insect Biochem Mol Biol 35(7): 729-739.

13. Rahman MM, Roberts HL, Sarjan M, Asgari S, Schmidt O (2004a) Induction and transmission of Bacillus thuringiensis tolerance in the flour moth Ephestia kuehniella. Proceeding of National Academy of Science 101(9): 2696-2699.

14. Rahman MM, Roberts HL, Schmidt O (2004b) Tolerance to Bacillus thuringiensis endotoxin in immune-suppressed larvae of the flour moth Ephestia kuehniella. J Invertebr Pathol 96(2): 125-132.

15. Tabashnik BE, Cushing NL, Johnson MW (1987) Diamondback moth Plutella xylostella Lepidoptera, Plutellidae) resistance to insecticides in Hawaii intra-island variation and cross-resistance. Journal of Economic Entomology 80(6): 1091-1099.

16. Tabashnik BE, Roush RT, Earle ED, Shelton AM (2000) Resistance to Bt-toxins. Science 287(5450): 7.

17. Bravo A, Gill SS, Soberon M (2007) Mode of action of Bacillus thuringiensis Cry and Cyt toxins and their potential for insect control. Toxicon 49(4): 423-435.

18. Ferre J, Van Rie J (2002) Biochemistry and Genetics of insect resistance to Bacillus thuringiensis. Annu Rev Entomol 47: 501-533. 
19. Dal-Bello G, Padin S, Lopez-Lastra C, Fabrizio M (2001) Laboratory evaluation of chemical-biological control of the rice weevil (Sitophilus oryzae L.) in stored grains. J Stored Prod Res 37(1): 77-84.

20. Hidalgo E, Moore D, Le Patourel G (1998) The effect of different formulations of Beauveria bassiana on Sitophilus zeamaisin on stored maize. Journal of Stored Products Research 34(2-3): 171-179.

21. Moino A, Alves SB, Pereira RM (1998) Efficacy of Beauveria bassiana (Balsamo) Vuillemin isolates for control of stored-grain pests. Journal of Applied Entomology 122(1-5): 301-305.

22. Odour GI, Smith SM, Chandi EA, Karanja LW, Agano JO, et al. (2000) Occurrence of Beauveria bassiana on insect pests of stored maize in Kenya. Journal of Stored Products Research 36(2): 177-185.

23. Padin SB, Bello GM, Vasicek AL, Dal-Bello G (1996) Bioinsecticide potential of entomopathogenic fungi for stored-grain pests. Revista de la Facultad de Agronomia-Universidad de Buenos Aires 15: 1-7.

24. Padin SB, Bello GM, Vasicek AL (1997) Pathogenicity of Beauveria bassiana for adults of Tribolium castaneum (Coleoptera: Tenebrionidae) in stored grains. Entomophaga 42(4): 569-577.

25. Padin SB, Dal-Bello GM, Fabrisio M (2002) Grain loss caused by Tribolium castaneum, Sitophilus oryzae, and Acanthoscelides obtecus in stored durum wheat and beans treated with Beauveria bassiana. Journal of Stored-Products Research 38(1): 69-74.

26. Rice WC, Cogburn RR (1999) Activity of the entomopathogenic fungus Beauveria bassiana (Deuteromycota: Hyphomycetes) against three coleopteran pests of stored grains. Journal of Economic Entomology 92(3): 691-694.

27. Sheeba G, Seshardi S, Raja N, Janarthana S, Ignacinutha S (2001) Efficacy of Beauveria bassiana for control of the rice weevil Sitophilus oryzae L. (Coleoptera: Curculionidae). Applied Entomology and Zoology 36(1): 117-120.

28. Batta YA (2003a) Production and testing of novel formulations of the entomopathogenic fungus Metarhizium anisopliae (Metschinkoff) Sorokin (Deuteromycotina: Hyphomycetes). Crop Protection 22(2): 415-422.

29. Batta YA (2003b) Symptomatology of tobacco whitefly and red spidermite infection with the entomopathogenic fungus Metarhizium anisopliae (Metch.) Sorokin. Dirasat: Agricultural Sciences 30(3): 294303.

30. Batta YA (2004) Control of rice weevil (Sitophilus oryzae L., Coleoptera: curculionidae) with various formulations of Metarhizium anisoplie. Crop Protection 23(2): 103-108.

31. Batta YA (2005) Control of the lesser grain borer (Rhyzopertha dominica F., Coleoptera: Bostrichidae) by treatments with residual formulations of Metarhizium anisopliae (Metch.) Sorokin (Deuteromycotina: Hyphomycetes). Journal of Stored Products Research 41(2): 221-229.

32. Batta YA (2007) Biocontrol of almond bark beetle (Scolytus amygdali Geurin-Meneville, Coleoptera: Scolytidae) using Beauveria bassiana (Bals.) Vuill. (Deuteromycotina: Hyphomycetes). J Appl Microbiol 103(5): 1406-1414.

33. Batta YA (2008) Control of main stored-grain insects with new formulations of entomopathogenic fungi in diatomaceous earth dusts. International Journal of Food Engineering 4(1): 16.

34. Batta YA, Abu Safieh DI (2005) A study of treatment effect with Metarhizium anisopliae and four types of dusts on wheat grain infestation with red flour beetles (Tribolium castaneum Herbs, Coleoptera: Tenebrionidae). The Islamic University Gaza Journal 13(1): 11-22.

35. Michalaki M, Athanassiou C, Kavallieratos N, Batta Y, Balotis G (2006) Effectiveness of Metarhizium anisopliae (Metschinkoff) Sorokin applied alone or in combination with diatomaceous earth against Tribolium confusum Du Val larvae: Influence of temperature, relative humidity and type of commodity. Crop Protection 25(5): 418-425.

36. Ibrahim YB, Low W (1993) Potential of mass-production and field efficacy of isolates of the entomopathogenic fungi Beauveria bassiana and Paecilomyces fumosoroseus against Plutella xylostella. International Journal of Pest Management 39(3): 288-292.

37. Sarfraz M, Keddie AB, Dosdall LM (2005) Biological control of the diamondback moth, Plutella xylostella: A review. Biocontrol Science and Technology 15(8): 763-789.

38. Selman BJ, Dayer S, Hasan M (1997) Pathogenicity of Beauveria bassiana (Bals.) Vuill. to the larvae of diamondback moth, Plutella xylostella L. (Lep., Yponomeutidae). Journal of Applied Entomology 121(1-5): 47-49.

39. Toshio M (2000) Microbial control of the Diamondback moth, Plutella xylostella, by an entomopathogenic fungus, Beauveria bassiana. II. Effect of temperature on mycoses and conidial invasion time. Japanese Journal of Applied Entomology and Zoology 44(3): 177-182.

40. LeOra software (1987) POLO-PC: A user's guide to Probit or logit analysis. Berkeley, CA, USA, p. 19.

41. Dos-Santos HJ, Marques EJ, Barros R, Gondim MG (2006) Interaction of Metarhizium anisopliae (Metsch.) Sorok., Beauveria bassiana (Bals.) Vuill. and the parasitoid Oomyzus sokolowskii (Kurdjumov) (Hymenoptera: Eulophidae) with larvae of diamondback moth, Plutella xylostella (L.) (Lepidoptera: Plutellidae). Neotrop Entomol 35(2): 241245.

42. Godonou I, James B, Atcha-Ahowe C, Vodouhè S, Kooyman C, et al. (2009) Potential of Beauveria bassiana and Metarhizium anisopliae isolates from Benin to control Plutella xylostella L. (Lepidoptera: Plutellidae). Crop Protection 28(3): 220-224.

43. Ortiz-Urquiza A, Keyhani NO (2013) Action on the surface: entomopathogenic fungi versus the insect cuticle. Insects 4(3): $357-$ 374.

44. Pedrini N, Crespo R, Juárez MP (2007) Biochemistry of insect epicuticle degradation by entomopathogenic fungi. Comparative Biochemistry and Physiology C: Toxicology and Pharmacology 146(1-2): 124-137.

45. Stephou VK, Tjamos SE, Paplomatas EJ, Athanassiou CG (2012) Transformation and attachment of Beauveria bassiana conidia on the cuticle of Tribolium confusum and Sitophilus oryzae in conjunction with diatomaceous earth. Journal of Pest Science 85(3): 387- 394.

46. Zhang YJ, Feng MG, Fan YH, Luo ZB, Yang XY, et al. (2008) Cuticle degrading protease (CDEP-1) of Beauveria bassiana enhances virulence. Biocontrol Science and Technology 18(6): 551-563.

47. Schunemann R, Knnak N, Fiuza LM (2014) Mode of Action and Specificity of Bacillus thuringiensis Toxins in the Control of Caterpillars and Stink Bugs in Soybean Culture. ISRN Microbiology. Article ID 135675, p. 12. 


\section{Your next submission with Juniper Publishers} will reach you the below assets

- Quality Editorial service

- Swift Peer Review

- Reprints availability

- E-prints Service

- Manuscript Podcast for convenient understanding

- Global attainment for your research

- Manuscript accessibility in different formats

( Pdf, E-pub, Full Text, Audio)

- Unceasing customer service

Track the below URL for one-step submission https://juniperpublishers.com/online-submission.php 